\title{
The SOD Gene Family in Tomato: Identification, Phylogenetic Relationships, and Expression Patterns
}

Kun Feng 1,2, Jiahong $\mathrm{Yu}^{2,3}$, Yuan Cheng ${ }^{2}$, Meiying Ruan'², Rongqing Wang ${ }^{2}$, Qingjing $\mathrm{Ye}^{2}$, Guozhi Zhou' ${ }^{2}$, Zhimiao $\mathrm{Li}^{2}$, Zhuping Yao ${ }^{2}$, Yuejian Yang ${ }^{2}$, Qingsong Zheng ${ }^{1 *}$ and Hongjian Wan ${ }^{2 *}$

\author{
'Key Laboratory of Marine Biology, College of Resources and Environmental Science, Nanjing Agricultural University, \\ Nanjing, China, ${ }^{2}$ State key Laboratory Breeding Base for Zhejiang Sustainable Pest and Disease Control, Institute of \\ Vegetables, Zhejiang Academy of Agricultural Sciences, Hangzhou, China, ${ }^{3}$ College of Chemistry and Life Science, Zhejiang \\ Normal University, Jinhua, China
}

\section{OPEN ACCESS}

Edited by:

Hinanit Koltai,

Agricultural Research Organization,

Israel

Reviewed by:

Natalie Brezinova Belcredi, Mendel University, Czech Republic

Paola Leonetti,

National Research Council, Italy

*Correspondence:

Qingsong Zheng

qszheng@njau.edu.cn

Hongjian Wan

wanhongjian@sina.com

Specialty section:

This article was submitted to Crop Science and Horticulture, a section of the journal

Frontiers in Plant Science

Received: 30 June 2016 Accepted: 11 August 2016 Published: 30 August 2016

Citation

Feng $K, Y$ U J, Cheng Y, Ruan $M$, Wang $R$, Ye $Q$, Zhou G, Li Z, Yao Z, Yang Y, Zheng $Q$ and Wan $H$ (2016)

The SOD Gene Family in Tomato: Identification, Phylogenetic

Relationships, and Expression

Patterns. Front. Plant Sci. 7:1279.

doi: 10.3389/fpls.2016.01279
Superoxide dismutases (SODs) are critical antioxidant enzymes that protect organisms from reactive oxygen species (ROS) caused by adverse conditions, and have been widely found in the cytoplasm, chloroplasts, and mitochondria of eukaryotic and prokaryotic cells. Tomato (Solanum lycopersicum L.) is an important economic crop and is cultivated worldwide. However, abiotic and biotic stresses severely hinder growth and development of the plant, which affects the production and quality of the crop. To reveal the potential roles of $S O D$ genes under various stresses, we performed a systematic analysis of the tomato $S O D$ gene family and analyzed the expression patterns of SISOD genes in response to abiotic stresses at the whole-genome level. The characteristics of the $S / S O D$ gene family were determined by analyzing gene structure, conserved motifs, chromosomal distribution, phylogenetic relationships, and expression patterns. We determined that there are at least nine SOD genes in tomato, including four Cu/ZnSODs, three FeSODs, and one MnSOD, and they are unevenly distributed on 12 chromosomes. Phylogenetic analyses of $S O D$ genes from tomato and other plant species were separated into two groups with a high bootstrap value, indicating that these SOD genes were present before the monocot-dicot split. Additionally, many ciselements that respond to different stresses were found in the promoters of nine SISOD genes. Gene expression analysis based on RNA-seq data showed that most genes were expressed in all tested tissues, with the exception of SISOD6 and SISOD8, which were only expressed in young fruits. Microarray data analysis showed that most members of the $S / S O D$ gene family were altered under salt- and drought-stress conditions. This genome-wide analysis of SISOD genes helps to clarify the function of SISOD genes under different stress conditions and provides information to aid in further understanding the evolutionary relationships of $S O D$ genes in plants.

Keywords: tomato, superoxide dismutase, SOD gene family, promoter, abiotic stress, gene expression 


\section{INTRODUCTION}

It is well known that toxic free radicals caused by environmental stresses such as cold, drought, and water-logging are great challenges for crop production (Mittler and Blumwald, 2010). Among them are reactive oxygen species (ROS), toxic free radicals produced in plant cells in response to stress, which can damage membranes, oxidize proteins, and cause DNA lesions (Sun et al., 2007; Wang and Prabakaran, 2011; Feng et al., 2015). However, in the process of evolution, plants have developed defense mechanisms to alleviate the damage caused by adverse environmental conditions. For example, some well-known ROSscavenging enzymes can defend plants against environmental stress by controlling the expression of enzyme responsive family genes, including superoxide dismutase (SOD), peroxidase (POD), catalase (CAT), glutathione peroxidase (GPX), and peroxiredoxin (PrxR) (Mittler et al., 2004; Filiz and Tombuloğlu, 2014).

Superoxide dismutases, a group of metalloenzymes, were first found in bovine erythrocytes in Mann and Keilin (1938). Subsequently, they were also described in bacteria, higher plants, and vertebrates (Rabinowitch and Sklan, 1980; Tepperman and Dunsmuir, 1990; Kim et al., 1996; Zelko et al., 2002). McCord and Fridovich (1969), researchers found that SODs can catalyze the dismutation of the superoxide $\mathrm{O}_{2}^{-}$to $\mathrm{O}_{2}$ and $\mathrm{H}_{2} \mathrm{O}_{2}$ (Tepperman and Dunsmuir, 1990). In plants, SODs have been detected in roots, leaves, fruits, and seeds (Giannopolitis and Ries, 1977; Tepperman and Dunsmuir, 1990), where they provide basic protection to cells against oxidative stress.

Based on their metal cofactors, protein folds, and subcellular distribution, SODs are mainly categorized as $\mathrm{Cu} / \mathrm{ZnSODs}$, FeSODs, and MnSODs (Alscher and Erturk, 2002; MolinaRueda et al., 2013; Filiz and Tombuloğlu, 2014; Feng et al., 2015). Cu/ZnSODs can be found in prokaryotic and eukaryotic organisms, were first isolated from Photobacterium leiognathi in Puget and Michelson (1974; Deshazer et al., 1994), and are present in the cytoplasm, chloroplasts, and/or the extracellular space in plant cells (Pilon et al., 2011). In mammalian cells, the molecular weight of $\mathrm{Cu} / \mathrm{ZnSODs}$ is about $32 \mathrm{kDa}$, and they can be found in cytoplasm, nuclear compartments, and lysosomes (Chang et al., 1988; Keller et al., 1991; Crapo et al., 1992; Liou et al., 1993). FeSODs have been found in plant chloroplasts and cytoplasm (Moran et al., 2003; Miller, 2012). MnSODs, widely present in all major kingdoms, have been observed in eukaryotic mitochondria (Lynch and Kuramitsu, 2000) and can protect mitochondria by scavenging ROS (Moller, 2001). MnSODs also play an important role in promoting cellular differentiation (Wispé et al., 1992; Clair et al., 1994). In addition, a new type of SOD, NiSOD, has been reported in Streptomyces (Youn et al., 1996). However, no evidence for NiSOD has been found in plants (Felisa et al., 2005).

In recent years, some studies have reported that SODs can protect plants against abiotic and biotic stresses, such as heat, cold, drought, salinity, abscisic acid and ethylene (Wang et al., 2004; Pilon et al., 2011; Asensio et al., 2012; Feng et al., 2015). Under various environmental stress conditions, researchers have found that different types of $S O D$ genes have different expression patterns. For example, under drought stress, expression patterns of banana genes MaMSD1A and MaCSD1B were completely opposite to one another (Feng et al., 2015). Moreover, SODs with the same metal cofactor did not always play the same role in different species. For example, while we found that expression of MnSODs was not altered under oxidative stress conditions in Arabidopsis, researchers found that MnSOD expressions were changed significantly under salt stress in pea and cold and drought stresses in wheat (Gómez et al., 1999; Wu et al., 1999; Baek and Skinner, 2003). These results show that different SOD genes have different expression patterns in plants in response to diverse environmental stresses. Additionally, researchers have also found that alternative splicing and miRNAs may participate in the regulation of SOD expression (Srivastava et al., 2009; Lu et al., 2011). To date, the SOD gene family has been described in many plant species, including Arabidopsis thaliana, Musa acuminata, Sorghum bicolor, and Populus trichocarpa (Kliebenstein and Last, 1998; Molina-Rueda et al., 2013; Filiz and Tombuloğlu, 2014; Feng et al., 2015).

Tomato is not only an important staple and economic crop, but also plays a vital role as an experimental model plant (Mueller et al., 2005). In previous studies, two SOD-coding cDNA sequences isolated from tomato leaves were identified as $\mathrm{Cu} / \mathrm{ZnSOD}$ genes and were found to be distributed on different chromosomes (Perl-Treves et al., 1990, 1988). Subsequently, the expression levels of two $\mathrm{Cu} / \mathrm{ZnSOD}$ genes in tomato organs during leaf growth and fruit ripening were reported (Perl-Treves and Galun, 1991). Further, Perl et al. (1993) found that overexpression of $\mathrm{Cu} / \mathrm{ZnSODs}$ in potato showed that transgenic plants exhibited increased tolerance to oxidative stress. Recently, great efforts have been made to explore the roles of SOD genes in improving tomato tolerance to various environmental stresses, such as heat, salt, drought, cold, and bacteria (Mazorra et al., 2002; Li, 2009; Sasidharan et al., 2013; Soydam et al., 2013; Aydin et al., 2014). In addition, several recent studies have indicated that SOD played an important role of hormone and insecticide stresses. For example, Bernal et al. (2009) detected that the expression level of cytosolic $\mathrm{Cu} / \mathrm{Zn}$-SOD was increased after 1 day of auxin treatment for tomato. Chahid et al. (2015) studied the activity of SOD in tomato in response to xenobiotics stresses such as alpha-cypermethrin, chlorpyriphos, and pirimicarb. As described above, SOD gene families have been widely implicated in responses to abiotic and biotic stresses in tomato. However, these studies have mainly concentrated on the expression of a single form of SOD enzyme and on changes in the enzymatic antioxidant system under various environmental stresses, and little has been reported on the SOD gene family in tomato.

To comprehensively understand the putative roles of $S O D$ genes in tomato, a systematic analysis of the SOD gene family was necessary at the whole-genome level. Recently, the whole-genome sequence of tomato was made available, which provided opportunities for analyzing the expression patterns and regulation mechanisms of the tomato SOD (SISOD) gene family in response to environment stresses. Hence, the objectives of this study were (i) to identify the SOD gene family in tomato; (ii) to analyze gene structure, duplication and expression patterns in different tomato tissues; (iii) to illustrate chromosomal locations 
and phylogenetic relationships with SODs from other plants; and (iv) to reveal the regulating mechanisms of the SISOD gene family under abiotic (salt and drought) stress by using real-time fluorescence quantitative PCR (qRT-PCR).

\section{MATERIALS AND METHODS}

\section{Identification of SOD Genes in Tomato and Other Plant Species}

In this study, two methods were used to identify potential SOD genes in tomato. First, the whole tomato genome was downloaded from Sol Genomics Network $\left(\mathrm{SGN}^{1}\right)$ and a local database was constructed using the software Bioedit 7.0 (Pan and Jiang, 2014). Four SOD amino acid sequences from Solanum lycopersicum (AF527880-CuSOD), S. tuberosum (EU545469FeSOD), Arabidopsis thaliana (AAM62550.1-MnSOD) and Musa acuminata AAA Group (AEZ56248.2-FeSOD) were used as a query against the local tomato amino acid database. Second, Hidden Markov Model (HMM) profiles of $\mathrm{Cu} / \mathrm{ZnSOD}$ (PF00080), Fe-MnSOD (PF00081, PF02777) were downloaded from $\mathrm{Pfam}^{2}$. A BlastP search was performed to retrieve candidate tomato SOD genes. For BlastP, $e$-value was set at $1 \mathrm{e}^{-5}$. All redundant putative SOD sequences were excluded. The remaining SOD sequences were examined for copper/zinc and iron/manganese SOD domains by the Pfam server ${ }^{2}$. Physicochemical characteristics of SOD amino acid sequences were predicted by the Protparam tool ${ }^{3}$, including molecular weight $(\mathrm{MW})$, and theoretical isoelectric point $(p I)$ (Gasteiger et al., 2005).

In addition, to reveal the evolutionary relationships between $S O D$ genes in different plant species, potential SOD genes from eight plant species were selected for phylogenetic analysis. Among them, SOD genes from four plant species (Vitis vinifera, Solanum tuberosum, Zea mays, and Panicum miliaceum) were identified using the same method above. The SOD genes of the remaining plant species (Poplar, Arabidopsis thaliana, Oryza sativa, Sorghum bicolor) were derived from previously published studies (Kliebenstein and Last, 1998; Dehury et al., 2012; MolinaRueda et al., 2013; Filiz and Tombuloğlu, 2014).

\section{Subcellular Localization, Conserved Motifs, and Gene Structure Analysis of SISOD Proteins}

Subcellular localization of SOD proteins from different plant species was obtained from the ProtComp9.0 server ${ }^{4}$ (Feng et al., 2015). Conserved motif analysis of SISOD genes was performed by the Multiple Em for Motif Elicitation (MEME Suite 4.11.1) server $^{5}$ (Bailey et al., 2009). We used the method described by Feng et al. (2015), except that the number of motifs was set to 8 . Intron/exon configurations of SISOD genes were determined via

\footnotetext{
${ }^{1}$ https://solgenomics.net/

${ }^{2}$ http://pfam.xfam.org/

${ }^{3} \mathrm{http} / / /$ web.expasy.org/

${ }^{4}$ http://linux1.softberry.com/

${ }^{5} \mathrm{http}: / /$ meme-suite.org/tools/meme
}

the Gene Structure Display Server ${ }^{6}$, for both coding sequences and genomic sequences (Hu et al., 2015).

\section{Chromosomal Location and Gene Duplication}

Information about chromosomal location of SISOD genes was obtained from the SGN database and gene duplications were identified by the Plant Genome Duplication Database (PGDD) ${ }^{7}$ (Singh and Jain, 2015). Tandemly duplicated SISOD genes were identified according to methods reported by previous researchers (Yang and Tuskan, 2008; Tuskan et al., 2006). Chromosomal locations of the SISOD genes were performed with the MapDraw V2.1 tool based on information from the SGN database (Huang et al., 2012). Sequence similarity of SODs was calculated using the program DNAMAN.

\section{Phylogenetic Tree Construction of SODs}

To investigate the phylogenetic relationships of SISOD genes, a total of 108 SOD protein sequences were identified from nine plant species. Among them, 24 SOD protein sequences were excluded owing to the SOD domains being incomplete. Multiple sequence alignments of the remaining 84 SOD amino acid sequences were performed with ClustalW (Higgins et al., 1996) using default parameters. A phylogenetic tree was constructed using the software MEGA5.04 via neighbor-joining method (Tamura et al., 2011). In the phylogenetic tree, the degree of support for a particular grouping pattern was evaluated using bootstrap (1000 replicates) value (Filiz et al., 2014). The tree was viewed with FigTree (v1.3.1).

\section{Promoter Sequence Analysis}

Regions 1,000 bp upstream from the start codons of each SISOD gene were downloaded from SGN. Then, cis-elements in promoters of each SISOD gene were predicted using the PlantCARE server (Postel et al., 2002).

\section{Expression Patterns of SISOD Genes Based on RNA-seq and Microarray Data}

For RNA-seq analysis, transcription data of the genome-wide gene expression of the tomato cultivar Helnz were downloaded from the tomato functional genomics database (TFGD) ${ }^{8}$ (Fei et al., 2011). Ten different tissues were selected: root, leaf, bud, flower, $1-\mathrm{cm}$ fruit, $2-\mathrm{cm}$ fruit, $3-\mathrm{cm}$ fruit, mature green fruit (MG), fruit at the fruit breaking stage (B), and fruit 10 days after the fruit breaking stage (B10). RPKM (Reads Per Kilo bases per Million mapped Reads) values of SISOD genes were log2transformed (Wei et al., 2012). Heat maps of SISOD genes in different tissues were generated using MeV4.9 software (Singh and Jain, 2015).

In addition, microarray data for salt and drought stresses were downloaded from the TOM2 cDNA array and Affymetrix Tomato Genome Array platform from TFGD (Fei et al., 2011).

\footnotetext{
${ }^{6}$ http://gsds.cbi.pku.edu.cn/

${ }^{7}$ http://chibba.agtec.uga.edu/duplication/

${ }^{8}$ http://ted.bti.cornell.edu/
} 
Probe sets corresponding to SISOD genes were identified using the Probe Match Tool in NetAffx Analysis Center ${ }^{9}$ (Altschul et al., 1997). A BlastN search was performed based on sequence alignment between probe sequences and SISOD sequences. Expression patterns of SISOD genes under salt and drought stresses were viewed using MeV4.9 software (Singh and Jain, 2015).

\section{Plant Materials and Stress Treatment}

Seeds of a tomato breeding strain, Zhe fen 202, were germinated on water-saturated filter paper. Before germinating, a $10 \%$ hypochlorous acid solution was used to sterilize seeds for 5 min. Then, seeds were washed three times with distilled water. Seedlings were grown on Hoagland nutrient solution, in a controlled chamber $\left(25^{\circ} \mathrm{C} / 20^{\circ} \mathrm{C}\right.$, day/night, $16 \mathrm{~h} / 12 \mathrm{~h}$ light/dark cycle). Upon development of the fourth true leaf, seedlings were cultivated in Hoagland nutrient solution with $150 \mathrm{mM}$ sodium chloride $(\mathrm{NaCl})$ and $18 \%$ polyethylene glycol (PEG) for treatment (3 and $12 \mathrm{~h}$ ), respectively. Leaves were collected and frozen in liquid nitrogen immediately and stored at $-80^{\circ} \mathrm{C}$. Three biological replications were carried out.

\section{RNA Extraction and qRT-PCR Data Analysis}

RNA extraction was performed using the RNAsimple Total RNA Kit (TIANGEN, Beijing, China) according to manufacturer instructions. Before reverse transcription, the quality of RNA samples was checked by agarose gel electrophoresis. All RNAs were reverse transcribed into cDNA using the FastQuant RT Kit with gDNase (TIANGEN, Beijing, China) according to manufacturer instructions.

Specific primers for qRT-PCR analysis were designed using the GenScript server ${ }^{10}$ (Supplementary Table S1) and were synthesized by Sangon Biotech (Shanghai). The GAPDH gene was used as an internal control (Expósito-Rodríguez et al., 2008). An ABI StepOne real time fluorescence quantitative PCR instrument (Applied Biosystems, American) was used for qRT-PCR analysis. The quality and specificity of primers was determined by the melt curve (Feng et al., 2015). Three independent technical replicates were performed for each of the SISOD genes. The PCR program consisted of an initial denaturation at $95^{\circ} \mathrm{C}$ for $15 \mathrm{~min}$, followed by 40 cycles of $95^{\circ} \mathrm{C}$ for $10 \mathrm{~s}, 55^{\circ} \mathrm{C}$ for $20 \mathrm{~s}$, and $72^{\circ} \mathrm{C}$ for $30 \mathrm{~s}$. The relative expression levels were calculated using the $2^{-\Delta \Delta \mathrm{Ct}}$ method, and were presented by histogram (Livak and Schmittgen, 2001).

\section{RESULTS}

\section{Genome-Wide Identification of SOD Genes Family in Tomato}

A total of nine SOD genes, classified into two major groups $(\mathrm{Cu} / \mathrm{ZnSODs}$ and Fe-MnSODs), were identified in tomato. The

${ }^{9}$ http://www.affymetrix.com

${ }^{10} \mathrm{https}$ //www.genscript.com/ssl-bin/app/primer former group included four members with a copper-zinc domain (SlSOD1, 2, 3, and 4); the latter was composed of five members with an iron/manganese SOD alpha-hairpin domain and an iron/manganese SOD, C-terminal domain (SISOD5, 6, 7, 8 and 9) (Table 1). The physicochemical analysis showed that the length of amino acid sequences, MW, and $p I$ values varied among these SISOD proteins. The length ranged from 152 to $311 \mathrm{AA}$, MW ranged from 15.3 to $34.6 \mathrm{kDa}$, and $p I$ ranged from 5.38 to 7.13 (Table 1). No significant difference in the acid-base properties of SISOD proteins was observed, except for SISOD9, which was slightly basic. Using the ProtComp9.0 program, subcellular localizations of SISOD proteins were determined. Among them, two Cu/ZnSODs (SlSOD1 and 2) and one FeMnSOD (SISOD8) were predicted to localize in the cytoplasm. One Fe-MnSOD (SlSOD9) was localized in mitochondrion. The remaining members were localized in the chloroplast.

\section{Conserved Motif Analysis of SISOD Proteins}

Four motifs in SISOD proteins (motif 1 to motif 4 ) were identified by MEME. Among them, three motifs (motifs 1, 3, and 4) were related to iron/manganese SOD domains, while motif 2 was related to copper/zinc SOD domains (Table 2). As shown in Figure 1, motif 2 was located in Cu/ZnSODs (SlSOD1, 2 and 3), except SISOD4; motif 1 and motif 3 were shared in Fe-MnSODs (SlSOD5, 6, 7, 8, and 9). Motif 4 was widely present in $\mathrm{Fe}$ MnSODs, except for SISOD8.

\section{Chromosomal Distribution and Intron/Exon Configurations of SISOD Genes}

The chromosomal distributions of nine SISOD genes were determined. As shown in Figure 2, six out of the twelve chromosomes harbored SISOD genes. Chromosome 6 and 3 possessed three and two SISOD genes, respectively, while each of the remaining four chromosomes (chromosome 1,2, 8, and 11) contained only one SISOD gene. Notably, chromosome 6 had one gene cluster (SlSOD5 and 8), which was identified as tandem duplication event. Segmental duplication was identified between SISOD5 (chromosome 6) and SISOD6 (chromosome 3) by PGDD database. However, despite the sequence similarity between SISOD5 and SISOD6, no tandem-duplicated paralogous genes were found in the region surrounding SISOD6.

Intron/exon configurations of SISOD genes were constructed using the Gene Structure Display Server (GSDS 2.0 ${ }^{11}$ ) by aligning the cDNA sequences with the corresponding genomic DNA sequences (Figure 3). We found that intron numbers among these SISOD genes ranged from 4 to 8 . Two SISOD genes (SISOD5 and 6) exhibited the highest intron number (8), whereas SISOD8 only had four introns (Table 1). In addition, two groups of SlSOD genes (SlSOD1 and 2, SISOD5 and 6) exhibited similar intron/exon organization patterns, respectively. The rest of the $S I S O D$ genes exhibited diverse intron/exon organization patterns.

\footnotetext{
${ }^{11}$ http://gsds.cbi.pku.edu.cn/index.php
} 
TABLE 1 | The characteristics of SOD genes from Solanum lycopersicum.

\begin{tabular}{|c|c|c|c|c|c|c|c|c|c|}
\hline $\begin{array}{l}\text { Gene } \\
\text { name }\end{array}$ & Sequence ID & Chromosome & $\begin{array}{l}\text { ORF } \\
\text { Length } \\
\text { (bp) }\end{array}$ & $\begin{array}{l}\text { Intron } \\
\text { number }\end{array}$ & $\begin{array}{l}\text { Length } \\
\text { (aa) }\end{array}$ & MW (KDA) & pl & $\begin{array}{c}\text { Predicted } \\
\text { Pfam domain }\end{array}$ & $\begin{array}{c}\text { Subcellular } \\
\text { prediction by } \\
\text { PC }\end{array}$ \\
\hline SISOD1 & Solyc01g067740.2 & 01 & 459 & 6 & 152 & 15.3 & 5.47 & $\mathrm{CZ}$ & Cytoplasm \\
\hline SISOD2 & Solyc03g062890.2 & 03 & 471 & 6 & 156 & 15.9 & 6.53 & $\mathrm{CZ}$ & Cytoplasm \\
\hline SISOD3 & Solyc11g066390.1 & 11 & 654 & 7 & 217 & 22.3 & 6.01 & $\mathrm{CZ}$ & Chloroplast \\
\hline SISOD4 & Solyc08g079830.2 & 08 & 936 & 5 & 311 & 32.9 & 6.45 & $\mathrm{HMA}, \mathrm{CZ}$ & Chloroplast \\
\hline SISOD7 & Solyc02g021140.2 & 02 & 759 & 7 & 252 & 29.1 & 6.65 & IMA,IMC & Chloroplast \\
\hline SISOD8 & Solyc06g048420.1 & 06 & 483 & 4 & 160 & 17.9 & 6.41 & IMA,IMC & Cytoplasm \\
\hline SISOD9 & Solyc06g049080.2 & 06 & 687 & 5 & 228 & 25.3 & 7.13 & IMA,IMC & Mitochondrion \\
\hline
\end{tabular}

MW, Molecular weight; pl, isoelectric points; CZ, copper/zinc superoxide dismutase (SODC); HMA, heavy-metal-associated domain; IMA, Iron/manganese superoxide dismutases alpha-hairpin domain; IMC, Iron/manganese superoxide dismutases, C-terminal domain; PC, ProtComp9.0 server.

TABLE 2 | Eight different motifs commonly observed in tomato protein sequences by MEME server.

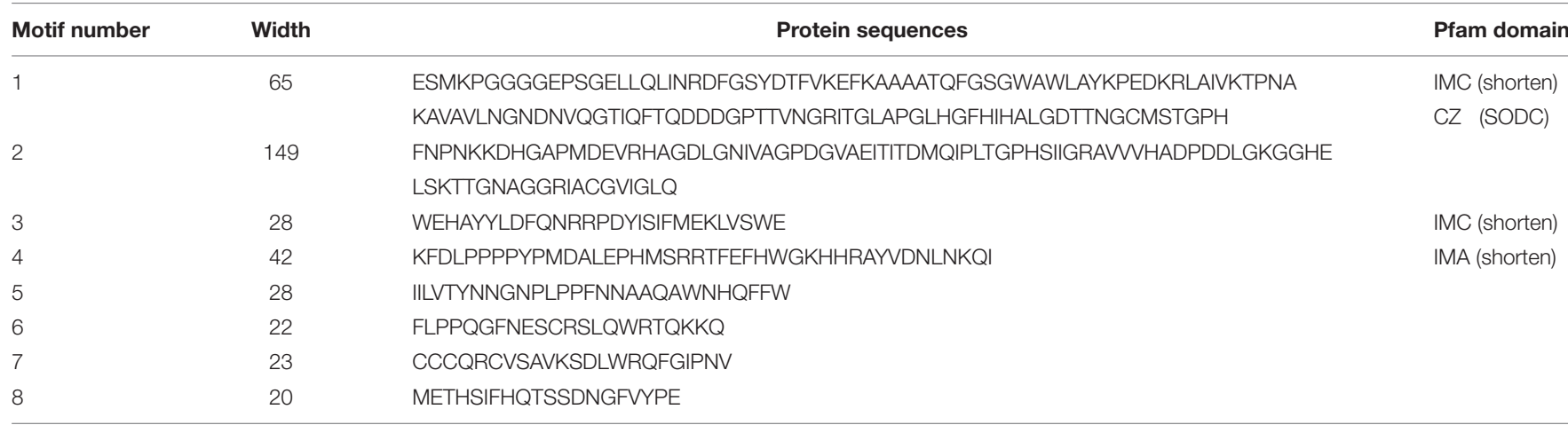

Among them, Pfam domain of four mitifs (motif5, 6, 7 and 8) were not identify by Pfam server. CZ, copper/zinc superoxide dismutase (SODC); IMA, Iron/manganese superoxide dismutases alpha-hairpin domain; IMC, Iron/manganese superoxide dismutases, C-terminal domain.

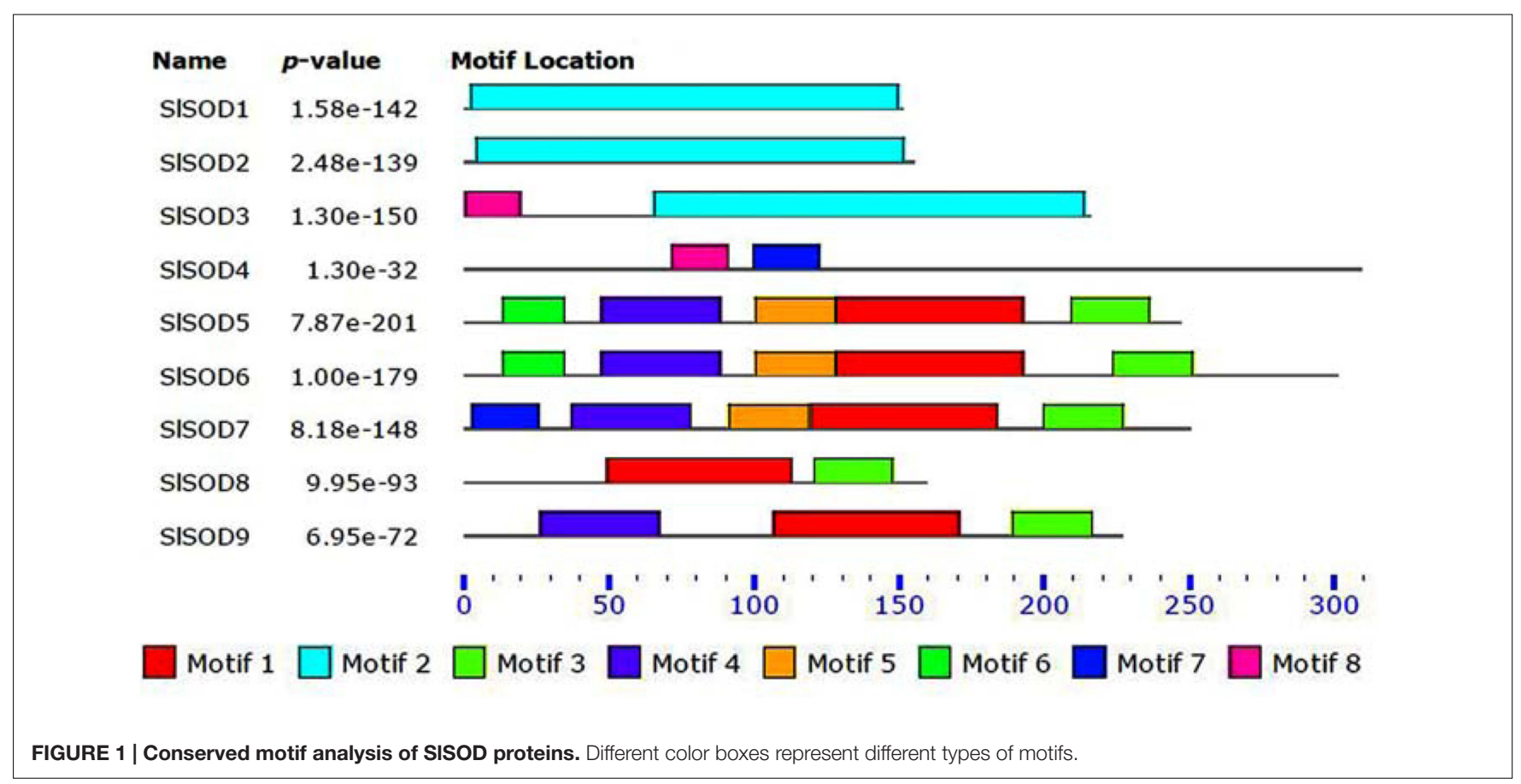




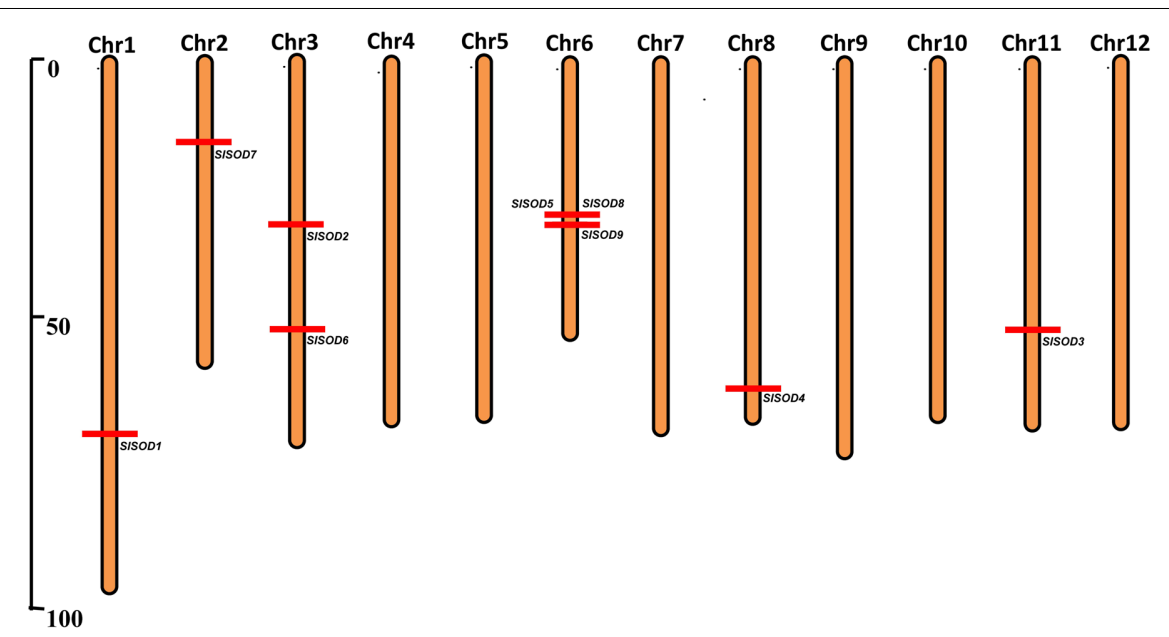

FIGURE 2 | Chromosomal locations of $\mathbf{9}$ SISOD genes on $\mathbf{1 2}$ chromosomes of tomato. Red lines represent the position of SISOD genes on chromosomes. The chromosome numbers are indicated at the top of chromosomes. The segment duplication event occurred between SISOD5 (chromosome 6 ) and SISOD6 (chromosome 3) and one cluster including tandemly duplicated genes (SISOD5 and SISOD8) on chromosome 6.

Legend:
CDS
FIGURE 3 I Intron/exon configurations of SISOD genes. Exons and introns are shown as yellow boxes and thin lines, respectively. UTRs are shown with blue
boxes. $0=$ intron phase $0 ; 1=$ intron phase $1 ; 2=$ intron phase 2.

\section{Phylogenetic Analysis of SOD Genes in Plants}

To investigate the phylogenetic relationships of SOD proteins between tomato and other plant species, a total of 108 SOD proteins were identified from S. lycopersicum, Populus trichocarpa, Arabidopsis thaliana, Vitis vinifera, S. tuberosum, O. sativa, Zea mays, Sorghum bicolor, and Panicum miliaceum. Among them, 24 SOD proteins were excluded due to incomplete SOD domains. An unrooted phylogenetic tree was constructed based on the remaining 84 SOD proteins using the program MEGA5.04 (Tamura et al., 2011). As shown in Figure 4, the SOD proteins from different plant species were divided into two major groups, $\mathrm{Cu} / \mathrm{ZnSODs}$ and Fe-MnSODs. The former group was subdivided into three subgroups ( $a, b$, and $c)$, and the latter was separated into two subgroups ( $\mathrm{d}$ and $\mathrm{e}$ ), which was strongly supported by high bootstrap values.

In our study, phylogenetic analysis showed that SISOD1 grouped with OsSOD1 (Loc-OsO3g22810), OsSOD2 (LocOs07g46990) and other plants' cytosolic Cu/ZnSODs clustered in subgroup a. SISOD4 grouped with OsSOD3 and other plants' chloroplastic $\mathrm{Cu} / \mathrm{ZnSODs}$ clustered in subgroup $\mathrm{c}$, while two
SISOD genes (SISOD2 and SISOD3) were clustered with other plants' cytosolic $\mathrm{Cu} / \mathrm{ZnSODs}$ and chloroplastic $\mathrm{Cu} / \mathrm{ZnSODs}$ in subgroup $b$, respectively. These results indicated that diversity in the $\mathrm{Cu} / \mathrm{ZnSODs}$ gene family occurred before the splitting of mono- and dicot plants. Interestingly, $\mathrm{Cu} / \mathrm{ZnSODs}$ genes in subgroup a were separated into mono- and dicot-specific branches, which suggested that they evolved independently after the splitting of mono- and dicot plants. In addition, FeSODs and MnSODs from different plant species were separated by a high bootstrap value (95\%). Four genes (SlSOD5, 6, 7, and 8) were clustered with other plants' chloroplastic FeSODs in subgroup $\mathrm{d}$ and SISOD9 was clustered with other plants' mitochondrial MnSODs in subgroup e.

\section{Analysis of Cis-Elements in Putative SISOD Gene Promoters}

To further understand gene function and regulation patterns, ciselements in SISOD gene promoter sequences were researched. Regions of 1,000 bp upstream from the start codons of each SISOD gene were determined using PlantCARE. The results showed that the cis-elements could be divided into three 


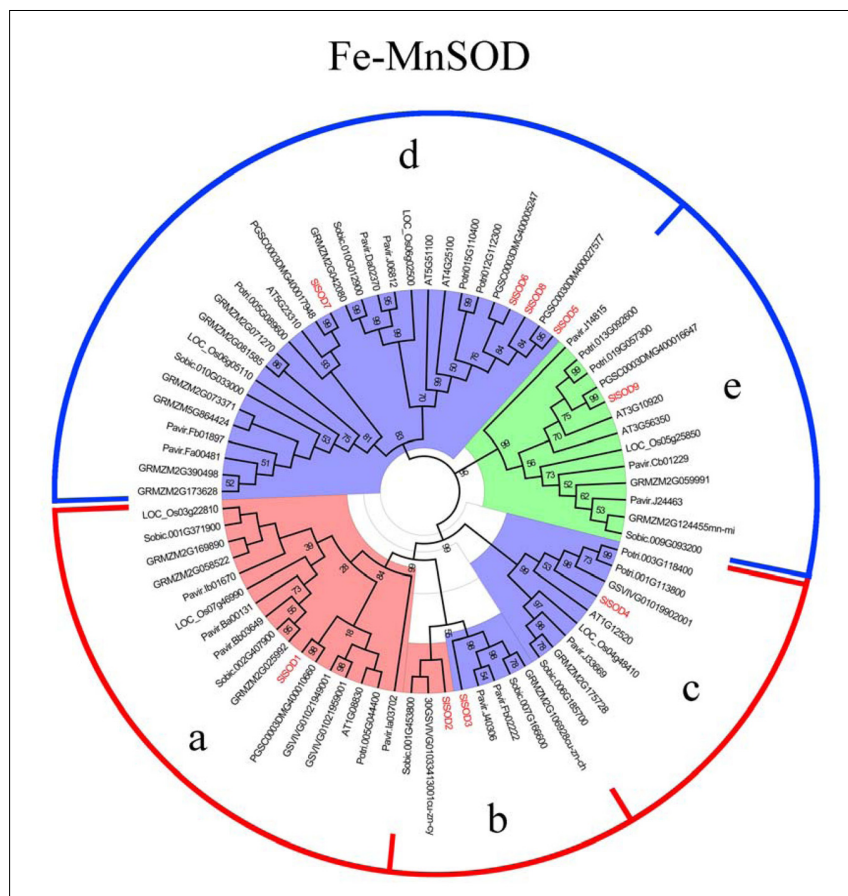

$\mathrm{Cu} / \mathrm{ZnSOD}$

FIGURE 4 | Phylogenetic tree of 84 SOD proteins from tomato and other plants including Populus trichocarpa, Arabidopsis thaliana, Vitis vinifera, S. tuberosum, O. sativa, Zea mays, Sorghum bicolor, and Panicum miliaceum. Two groups (Cu/ZnSODs and Fe-MnSOD) were identified and the tree was divided into five groups ( $a, b, c, d$ and e) based on high bootstrap values. SISOD proteins are marked in red. Three colors (coral, light blue and light green) represent the subcellular locations of SOD proteins: coral represents proteins localized in the cytoplasm, light blue represents proteins localized in chloroplasts, and light green represents proteins localized in mitochondria.

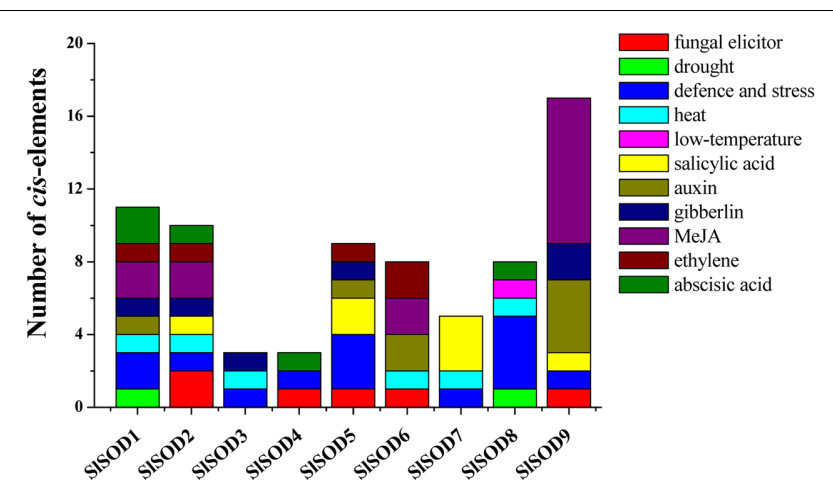

FIGURE 5 | Cis-elements in the promoters of putative SISOD genes that are related to stress responses. Different cis-elements with the same or similar functions are present with the same color.

major classes: stress-responsive, hormone-responsive, and lightresponsive. Six stress-responsive cis-elements were identified, including HSE, MBS, LTR, TC-rich, ARE and Box-W1, which reflected plant responses to heat, drought, low-temperature, defense stresses, anaerobic induction and fungal elicitors, respectively. Ten kinds of hormone-responsive cis-elements were identified (e.g., salicylic acid-SA, methyl jasmonateMeJA, gibberellins-GA, auxin-IAA, and ethylene) (Figure 5). A relatively large number of light-responsive cis-elements in SlSOD promoters was observed (Supplementary Table S2).

\section{Expression Analysis of SISOD Genes in Different Tissues}

To explore the expression patterns of $S O D$ genes during tomato growth and development, expression profiles were analyzed for 10 different tissues (root, leaf, bud, flower, $1-\mathrm{cm}$ fruit, $2-\mathrm{cm}$ fruit, 3-cm fruit, MG, B, and B10) of the tomato cultivar Helnz using the RNA-seq atlas. As shown in Figure 6A, five SISOD genes (SlSOD1, 2, 3, 4 and 9) had similar expression patterns in all the tested tissues, while two genes (SlSOD6 and 8) displayed distinct tissue-specific expression patterns. Interestingly, SISOD1 demonstrated a consistently high expression in all ten tissues, whereas SISOD6 and 8 were mainly expressed in young fruit. In addition, SISOD7 was expressed strongly in young fruit, weakly in root and moderately in the other tissues.

\section{Expression Patterns of SISOD Genes in Response to Abiotic Treatments}

To gain further insight into the role of SISOD genes under abiotic stress, we analyzed the expression profiles of SISOD genes in response to salt and drought stresses using microarray data. A total of 17 independent tomato microarray probes were identified by means of a BlastN search. As shown in Figure 6B, expression of SISOD genes was significantly altered under different abiotic stress treatments. For the salt treatment, eight probes corresponding to SISOD genes were found, with the exception being SISOD7. Expression of four SISOD genes (SISOD2, 5, 6, and 8) were down-regulated, and expression of three SISOD genes (SISOD3, 4, and 9) remained constant. Notably, SISOD1 was significantly up-regulated. For the drought treatment, microarray probes for each SISOD gene were identified. Four SlSOD genes (SlSOD2, 5, 6, and 8) were up-regulated and three (SISOD3, 4, and 9) were down-regulated (Figure 6C). Notably, SISOD6 expression increased twofold. SISOD1 and SISOD7 were unchanged. We found that the expression levels of most of the SISOD genes changed significantly under salt and drought stresses.

\section{Verification of SISOD Gene Expression Patterns with qRT-PCR}

To further verify the expression profiles of SISOD genes determined by microarray data analysis, qRT-PCR was used to analyze expression patterns of the nine SISOD genes under salt and drought stresses. As shown in Figure 7, most of the SISOD gene results were consistent with the microarray patterns. In response to salt treatment, expression levels of most SISOD genes were down-regulated, in accordance with the microarray profiles. However, expression patterns of three SISOD genes (SlSOD1, 6 and 9) determined by qRT-PCR analysis were different than those determined using the microarray profiles. We found that 


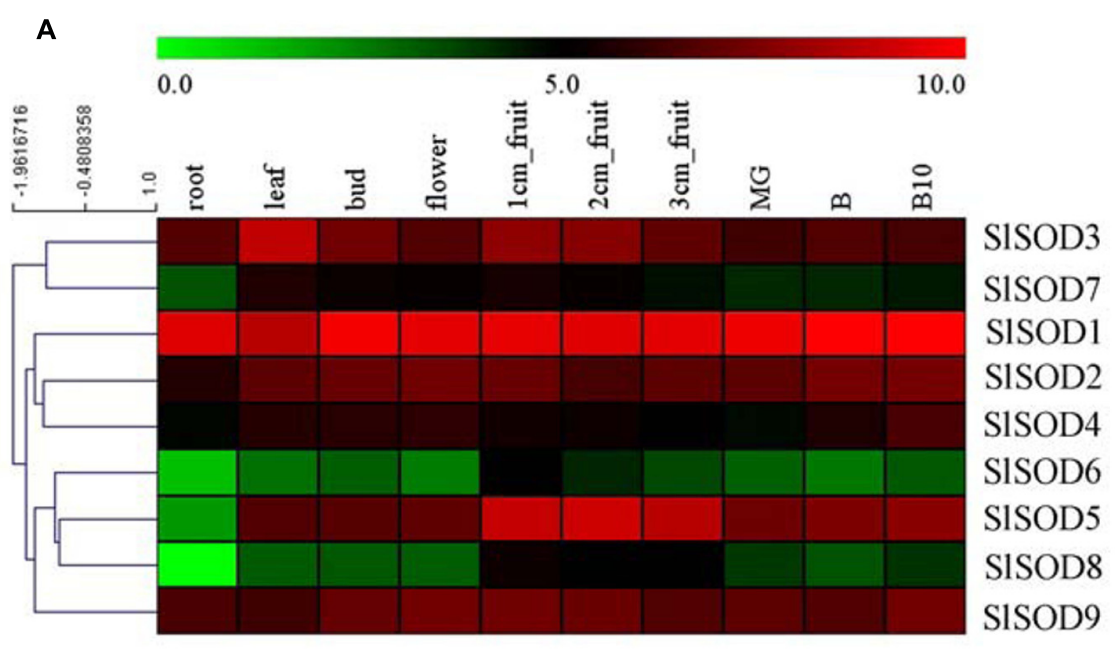

B

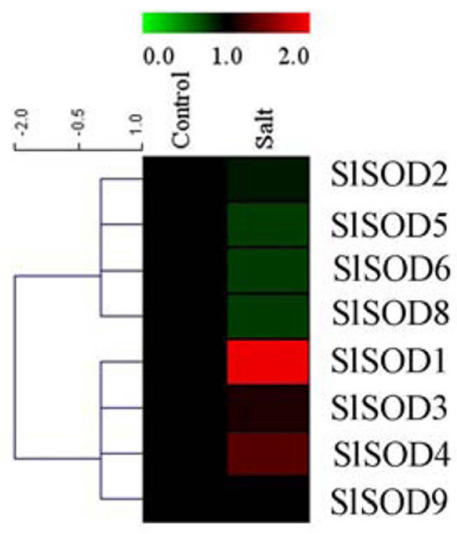

C

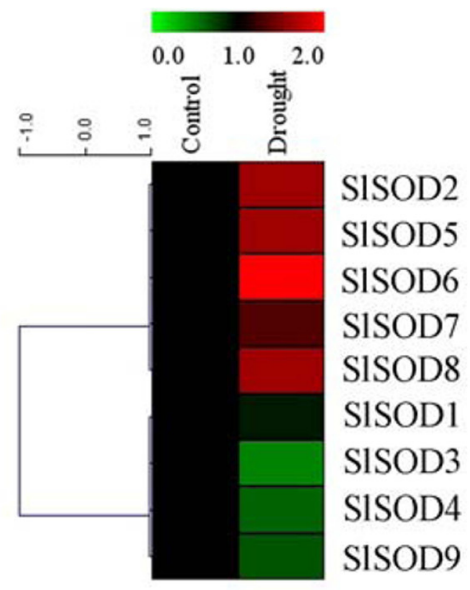

FIGURE 6 | Expression profiles of SISOD genes in different tomato tissues and under various biotic and abiotic stresses. (A) The expression patterns of SISOD genes in different tissues. The tested tissues are: root, leaf, bud, flower, $1 \mathrm{~cm}$ - fruit, $2 \mathrm{~cm}$ - fruit, $3 \mathrm{~cm}$-fruit, mature green fruit (MG), fruit breaking (B), 10 days after fruit breaking (B10). (B) Expression profiles of SISOD genes under salt stress. (C) Expression profiles of SISOD genes under drought stress.

in response to salt treatment, there was enhanced expression of SISOD6 and SISOD9 and a decreased transcript level of SISOD1. In response to drought treatment, expression levels of five SISOD genes (SISOD1, 3, 4, 6, and 7), were consistent with the microarray data. However, in contrast to our microarray results, qRT-PCR analysis showed down-regulation of three SISOD genes (SlSOD2, 5, and 8) and up-regulation of SISOD9.

\section{DISCUSSION}

Environmental stresses pose considerable challenges for crop production. Gene expression and SOD enzyme activities are influenced by environmental stresses such as high salinity, drought and metal toxicity (Schützendübel and Polle, 2002; Atkinson et al., 2013). However, plants have evolved defense mechanisms to alleviate the damage caused by adverse environmental conditions. Tomato, an important staple and economic crop, is affected by various abiotic stresses (Mueller et al., 2005). SODs are key enzymes in many oxidation processes, and provide basic protection against ROS in plants (Alscher and Erturk, 2002). Therefore, a systematic analysis of the SISOD gene family was performed and gene expression patterns were determined for plants under various abiotic stresses.

In this study, nine SISOD genes (four Cu/ZnSODs, four FeSODs, and one MnSOD) were identified in the tomato genome, including all three major types of plant SOD genes. Chromosome location analysis revealed that SISOD5 and SISOD8 formed 

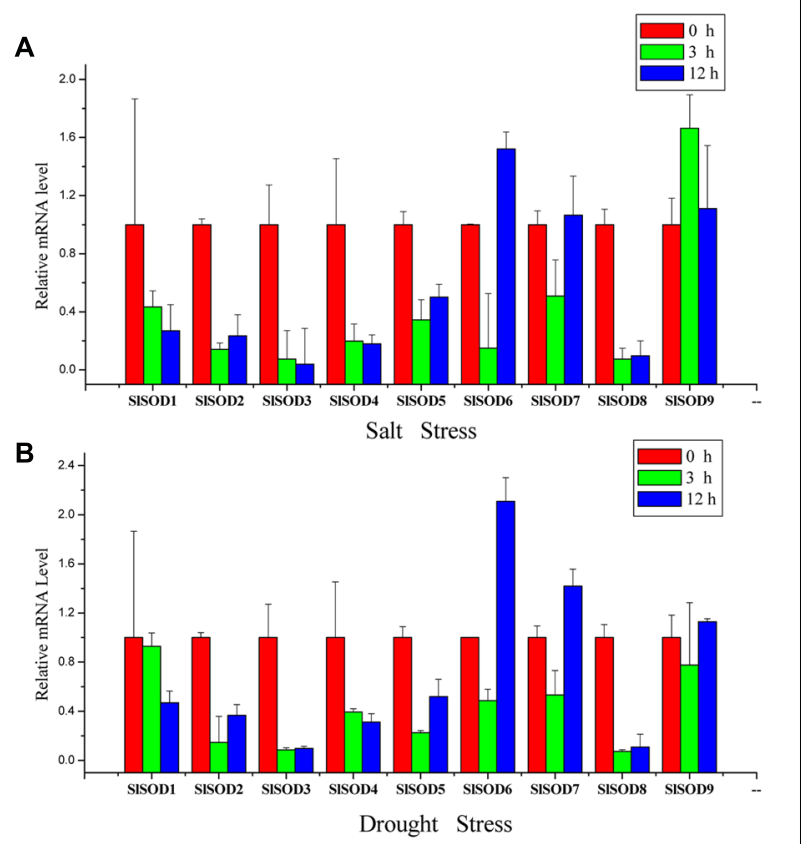

FIGURE 7 | Gene expression profiles of SISOD genes in response to salt and drought treatments using qRT-PCR. (A) Expression patterns of $S I S O D$ genes under salt stress conditions. (B) Expression patterns of $S / S O D$ genes under drought stress condition. Error bars represent standard deviations from three independent technical replicates.

a gene cluster on chromosome 6 and identified as tandem duplicated event. Segmental duplication was identified between SISOD5 (chromosome 6) and SISOD6 (chromosome 3) by PGDD. Although SISOD5 and SISOD6 have similar sequence, no tandem duplicated events were occurred in the region surrounding SISOD6. Considering the lower sequence similarity of SISOD5 to SISOD6 than that of SISOD5 to SlSOD8, it appears that segmental duplication events predate the tandem duplication in the SISOD5 and SISOD8 gene cluster (Supplementary Table S3). Therefore, we concluded that segmental duplication and tandem duplication played key roles in the expansion of SOD genes in the tomato genome.

Gene structure analysis revealed that the intron number of SISOD genes ranges from 4 to 8 . Previous researchers reported that intron patterns of plant $S O D$ genes were highly conserved, and that all cytosolic and chloroplastic SOD genes included seven introns except for one member (Fink and Scandalios, 2002; Filiz and Tombuloğlu, 2014). However, in this study, we observed that the intron numbers of six out of eight SISOD genes (excepting SlSOD9) were varied, and only two SISOD genes (SlSOD3, chloroplastic Cu/ZnSOD and SlSOD7, chloroplastic FeSOD) included seven introns. Thus, our data did not support the previous reports of plant $S O D$ gene intron patterns. Variation in exon-intron structures was accomplished by three main mechanisms (exon/intron gain/loss, exonization/pseudoexonization and insertion/deletion), each of which contributed to structural divergence (Xu et al., 2012; Filiz and Tombuloğlu, 2014). Moreover, two groups of SISOD genes (SlSOD1 and 2, SlSOD5 and 6) exhibited similar intron/exon organization patterns, respectively, which suggested high conservation in the evolutionary process.

Phylogenetic analysis showed that FeSODs and MnSOD from different plant species were separated by a high bootstrap value (95\%). This result was in agreement with previous report (Fink and Scandalios, 2002). In plants, MnSODs had 70\% homology but were different from FeSODs, which suggested that they originated from different ancestral genes (Miller, 2012). These data were well support our results that FeSODs and MnSOD of tomato were diverged with $95 \%$ bootstrap value.

To better understand the role of SISOD genes under various environmental stresses, cis-elements in the promoter sequences were predicted by PlantCARE server. The results showed that three major classes of cis-elements were identified, including stress-responsive, hormone-responsive, and light-responsive. Many identified cis-elements in the promotes of SISOD genes were related to heat, drought, low-temperature, defense stresses, anaerobic induction, fungal elicitors, SA, MeJA, GA, IAA and ethylene. As previously stated, cis-elements play an important role in plant stress responses; cis-elements such as ABRE, DRE, CRT, SARE and SURE respond to abscisic acid (ABA), dehydration, cold, SA, and sulfur, respectively (Sakuma et al., 2002; Maruyama-Nakashita et al., 2005; Shi et al., 2010; Osakabe et al., 2014). Thus, these results will contribute to further understand the various function role of SISOD genes under complex abiotic stress conditions.

To further clarify the potential functions of SISOD genes, expression profiles of all the SISOD genes in different tissues were analyzed. Based on RNA-seq, nine SISOD genes exhibited two disparate expression patterns: constitutive and tissue-specific expression patterns of SISOD genes. During tomato growth and development, two genes (SISOD1 and 9) sustained high expression in all the tested tissues. Two genes (SISOD6 and 8) demonstrated a tissue-specific expression pattern, being mainly expressed in young fruits. SlSOD7 was expressed strongly in young fruit tissue, weakly in root tissue, and moderately in the rest of the tissues tested.

Under various natural conditions, plant growth and development are frequently affected by high salinity, drought, cold, bacteria, and insecticides (Xia et al., 2012). Previous researchers reported that three types of SODs $(\mathrm{Cu} / \mathrm{ZnSODs}$, FeSODs and MnSODs) have been exploited to eliminate ROS caused by abiotic stress (Kliebenstein and Last, 1998; Wu et al., 1999). To further clarify the putative roles of SOD genes in tomato response to abiotic stresses, we examined the expression patterns of nine SISOD genes under salt and drought treatment conditions using microarray and qRT-PCR.

The results showed that the expression patterns of most SISOD genes obtained by qRT-PCR were in conformity with those obtained from the microarray analysis. Expression analysis revealed that most SISOD gene expression levels were changed in response to two abiotic stresses (salt and drought). For salt treatment, SISOD1 was the only gene that showed significant up-regulation among the nine SISOD genes, demonstrating that the function of SISOD1 relates to salt stress. Compared to the other SISOD genes, a greater variety and quantity of cis-elements 
were found in the promoter for SISOD1, including two TCrich motifs, an HSEs motif, and an MBS motif, which had been demonstrated to responsible for abiotic stress in banana (Feng et al., 2015). This could explain why SISOD1 expression changed significantly under salt treatment. Moreover, although many ciselements related to abiotic stresses were also found in the SISOD8 promoter, SISOD8 expression was significantly down-regulated under salt treatment. This suggested that some unidentified ciselement could play a vital role in regulating the expression of the SOD gene family in tomato under abiotic stress. Similar results have also been found in other plant species (Singh and Jain, 2015).

Additionally, we observed different expression patterns of SISOD genes under salt and drought stress conditions (Figure 6). For example, the expression of four SISOD genes (SISOD2, 5, 6, and 8) decreased during the salt treatment, while increased expression levels were observed for these four genes in response to drought treatment. This suggested that different SOD genes in tomato could play different roles in eliminating ROS caused by different environment stresses.

Taken together, the data we obtained provides more information about the $S O D$ gene family in tomato including sequence information, gene duplications, conserved motifs, gene structures, and phylogenetic relationships. Promoter analysis and complex regulation patterns of the SISOD genes under abiotic stress contribute to our understanding of the expression patterns of SOD genes in plants and provide clues for further

\section{REFERENCES}

Alscher, R. G., and Erturk, N. (2002). Role of superoxide dismutases (SODs) in controlling oxidative stress in plants. J. Exp. Bot. 53, 1331-1341. doi: 10.1093/jexbot/53.372.1331

Altschul, S. F., Madden, T. L., Schäffer, A. A., Zhang, J., Zhang, Z., Miller, W., et al. (1997). Gapped blast and psi-blast: a new generation of protein database search programs. Nucleic Acids Res. 25, 3389-3402. doi: 10.1093/nar/25.17.3389

Asensio, A. C., Gil-Monreal, M., Pires, L., Gogorcena, Y., Aparicio-Tejo, P. M., and Moran, J. F. (2012). Two Fe-superoxide dismutase families respond differently to stress and senescence in legumes. J. Plant Physiol. 169, 1253-1260. doi: 10.1016/j.jplph.2012.04.019

Atkinson, N. J., Lilley, C. J., and Urwin, P. E. (2013). Identification of genes involved in the response of Arabidopsis to simultaneous biotic and abiotic stresses. Plant Physiol. 162, 2028-2041. doi: 10.1104/pp.113.222372

Aydin, S., Büyük, İ., and Aras, E. S. (2014). Expression of SOD gene and evaluating its role in stress tolerance in $\mathrm{NaCl}$ and PEG stressed Lycopersicum esculentum. Turk. J. Bot. 38, 89-98. doi: 10.3906/bot-1305-1

Baek, K. H., and Skinner, D. Z. (2003). Alteration of antioxidant enzyme gene expression during cold acclimation of near-isogenic wheat lines. Plant Sci. 165, 1221-1227. doi: 10.1016/S0168-9452(03)00329-7

Bailey, T. L., Boden, M., Buske, F. A., Frith, M., Grant, C. E., Clementi, L., et al. (2009). MEME SUITE: tools for motif discovery and searching. Nucleic Acids Res. 37, W202-W208. doi: 10.1093/nar/gkp335

Bernal, A., Torres, J., Reyes, A., and Rosado, A. (2009). Exogenous auxin regulates $\mathrm{H}_{2} \mathrm{O}_{2}$ metabolism in roots of tomato (Lycopersicon esculentum mill.) seedlings affecting the expression and activity of $\mathrm{CuZn}$-superoxide dismutase, catalase, and peroxidase. Acta Physiol. Plant. 31, 249-260. doi: 10.1007/s11738-0080225-8

Chahid, K., Laglaoui, A., Zantar, S., and Ennabili, A. (2015). Antioxidant-enzyme reaction to the oxidative stress due to alpha-cypermethrin, chlorpyriphos, and studies of the roles of SOD genes under different stress conditions.

\section{AUTHOR CONTRIBUTIONS}

Conceived and designed the experiments: HW, QZ, and KF. Performed the experiments: KF, JY, YC, MR, RW, QY, GZ, ZY, and YY. Analyzed the data: KF, JY, and ZL. Wrote the paper: KF and HW. All authors have read and approved the manuscript.

\section{ACKNOWLEDGMENTS}

Research is supported by National Natural Science Foundation of China (31301774, 31272156, and 3150110311), Zhejiang Provincial Natural Science Foundation of China (Q15C150010), and Young Talent Cultivation Project of Zhejiang Academy of Agricultural Sciences (2015R23R08E07, 2015R23R08E09), Public Agricultural Technology Research in Zhejiang (2016C32101, 2015C32049), and Technological System of Ordinary Vegetable Industry (CARS-25-G-16).

\section{SUPPLEMENTARY MATERIAL}

The Supplementary Material for this article can be found online at: http://journal.frontiersin.org/article/10.3389/fpls.2016.01279

pirimicarb in tomato (Lycopersicon esculentum, Mill.). Environ. Sci. Pollut. Res. Int. 22, 18115-18126. doi: 10.1007/s11356-015-5024-3

Chang, L. Y., Slot, J. W., Geuze, H. J., and James, D. C. (1988). Molecular immunocytochemistry of the CuZn superoxide dismutase in rat hepatocytes. J. Cell Biol. 107, 2169-2179. doi: 10.1083/jcb.107.6.2169

Clair, D. K. S., Oberley, T. D., Muse, K. E., and Clair, W. H. S. (1994). Expression of manganese superoxide dismutase promotes cellular differentiation. Free Radic. Biol. Med. 16, 275-282. doi: 10.1016/0891-5849(94)90153-8

Crapo, J. D., Oury, T., Rabouille, C., Slot, J. W., and Chang, L. Y. (1992). Copper, zinc superoxide dismutase is primarily a cytosolic protein in human cells. Proc. Natl. Acad. Sci. U.S.A. 89, 10405-10409. doi: 10.1073/pnas.89.21.10405

Dehury, B., Sarma, K., Sarmah, R., Sahu, J., Sahoo, S., Sahu, M., et al. (2012). In silico analyses of superoxide dismutases (SODs) of rice (Oryza sativa L.). J. Plant Biochem. Biotechnol. 22, 150-156. doi: 10.1007/s13562-012-0121-6

Deshazer, D., Barnnan, J. D., Moran, M. J., and Friedman, R. L. (1994). Characterization of the gene encoding superoxide dismutase of Bordetella pertussis and construction of a SOD-deficient mutant. Gene 142, 85-89. doi: 10.1016/0378-1119(94)90359-X

Expósito-Rodríguez, M., Borges, A. A., Borges-Pérez, A., and Pérez, J. A. (2008). Selection of internal control genes for quantitative real-time RT-PCR studies during tomato development process. BMC Plant Biol. 8:131. doi: 10.1186/14712229-8-131

Fei, Z., Joung, J. G., Tang, X., Zheng, Y., Huang, M., Lee, J. M., et al. (2011). Tomato functional genomics database: a comprehensive resource and analysis package for tomato functional genomics. Nucleic Acids Res. 39, 1156-1163. doi: 10.1093/nar/gkq991

Felisa, W., Daniel, G., Oscar, S., and Falkowski, P. G. (2005). The role and evolution of superoxide dismutases in algae. J. Phycol. 41, 453-465. doi: 10.1111/j.15298817.2005.00086.x

Feng, X., Lai, Z., Lin, Y., Lai, G., and Lian, C. (2015). Genome-wide identification and characterization of the superoxide dismutase gene family in 
Musa acuminata cv. Tianbaojiao (AAA group). BMC Genomics 16:823. doi: 10.1186/s12864-015-2046-7

Filiz, E., Koç, İ., and Tombuloğlu, H. (2014). Genome-wide identification and analysis of growth regulating factor genes in Brachypodium distachyon: in silico approaches. Turk. J. Biol. 38, 296-306. doi: 10.3906/biy-1308-57

Filiz, E., and Tombuloğlu, H. (2014). Genome-wide distribution of superoxide dismutase (SOD) gene families in Sorghum bicolor. Turk. J. Biol. 39, 49-59. doi: 10.3906/biy-1403-9

Fink, R. C., and Scandalios, J. G. (2002). Molecular evolution and structurefunction relationships of the superoxide dismutase gene families in angiosperms and their relationship to other eukaryotic and prokaryotic superoxide dismutases. Arch. Biochem. Biophys. 399, 19-36. doi: 10.1006/abbi.2001.2739

Gasteiger, E., Hoogland, C., Gattiker, A., Duvaud, S., Wilkins, M. R., Appel, R. D., et al. (2005). "Protein identification and analysis tools on the expasy server" in Proteomics Protocols Handbook, ed. J. M. Walker (Totowa, NJ: Humana Press), 571-607.

Giannopolitis, C. N., and Ries, S. K. (1977). Superoxide dismutase: I. Occurrence in higher plants. Plant Physiol. 59, 309-314.

Gómez, J. M., Hernández, J. A., Jiménez, A., del Río, L. A., and Sevilla, F. (1999). Differential response of antioxidative enzymes of chloroplasts and mitochondria to long-term $\mathrm{NaCl}$ stress of pea plants. Free Radic. Res. 31(Suppl. 1), 11-18. doi: 10.1080/10715769900301261

Higgins, D. G., Thompson, J. D., and Gibson, T. J. (1996). Using CLUSTAL for multiple sequence alignments. Methods Enzymol. 266, 383-402. doi: 10.1016/S0076-6879(96)66024-8

Hu, B., Jin, J., Guo, A. Y., Zhang, H., Luo, J., and Gao, G. (2015). GSDS 2.0: an upgraded gene feature visualization server. Bioinformatics 31, 1296-1297. doi: 10.1093/bioinformatics/btu817

Huang, S., Gao, Y., Liu, J., Peng, X., Niu, X., Fei, Z., et al. (2012). Genome-wide analysis of WRKY transcription factors in Solanum lycopersicum. Mol. Genet. Genomics 287, 495-513. doi: 10.1007/s00438-012-0696-6

Keller, G. A., Warner, T. G., Steimer, K. S., and Hallewell, R. A. (1991). Cu, $\mathrm{Zn}$ superoxide dismutase is a peroxisomal enzyme in human fibroblasts and hepatoma cells. Proc. Natl. Acad. Sci. U.S.A. 88, 7381-7385. doi: 10.1073/pnas.88.16.7381

Kim, E. J., Kim, H. P., Hah, Y. C., and Roe, J. H. (1996). Differential expression of superoxide dismutases containing $\mathrm{Ni}$ and $\mathrm{Fe} / \mathrm{Zn}$ in Streptomyces coelicolor. Eur. J. Biochem. 241, 178-185. doi: 10.1111/j.1432-1033.1996.0178t.x

Kliebenstein, D. J., and Last, R. L. (1998). Superoxide dismutase in Arabidopsis: an eclectic enzyme family with disparate regulation and protein localization. Plant Physiol. 118, 637-650. doi: 10.1104/pp.118.2.637

Li, Y. (2009). Physiological responses of tomato seedlings (lycopersicon esculentum) to salt stress. Mod. Appl. Sci. 3, 171-176. doi: 10.5539/mas.v3n3p171

Liou, W., Chang, L. Y., Geuze, H. J., Strous, G. J., Crapo, J. D., and Slot, J. W. (1993). Distribution of CuZn superoxide dismutase in rat liver. Free Radic. Biol. Med. 14, 201-207. doi: 10.1016/0891-5849(93)90011-I

Livak, K. J., and Schmittgen, T. D. (2001). Analysis of relative gene expression data using real-time quantitative PCR and the $2^{-\Delta \Delta \mathrm{ct}}$ method. Methods 25 , 402-408. doi: 10.1006/meth.2001.1262

Lu, Y., Feng, Z., Bian, L., Xie, H., and Liang, J. (2011). miR398 regulation in rice of the responses to abiotic and biotic stresses depends on CSD1 and CSD2 expression. Funct. Plant Biol. 38, 44-53. doi: 10.1071/FP10178

Lynch, M., and Kuramitsu, H. (2000). Expression and role of superoxide dismutases (SOD) in pathogenic bacteria 1. Microbes Infect. 2, 1245-1255. doi: 10.1016/S1286-4579(00)01278-8

Mann, T., and Keilin, D. (1938). Haemocuprein and hepatocuprein, copper-protein compounds of blood and liver in mammals. Proc. R. Soc. B 126, 303-315. doi: 10.1098/rspb.1938.0058

Maruyama-Nakashita, A., Nakamura, Y., Watanabe-Takahashi, A., Inoue, E., Yamaya, T., and Takahashi, H. (2005). Identification of a novel cis -acting element conferring sulfur deficiency response in Arabidopsis roots. Plant J. 42, 305-314. doi: 10.1111/j.1365-313X.2005.02363.x

Mazorra, L. M., Núñez, M., Hechavarria, M., Coll, F., and Sánchez-Blanco, M. J. (2002). Influence of brassinosteroids on antioxidant enzymes activity in tomato under different temperatures. Biol. Plant 45, 593-596. doi: 10.1023/A:1022390917656
McCord, J. M., and Fridovich, I. (1969). Superoxide dismutase. An enzymic function for erythrocuprein (hemocuprein). J. Biol. Chem. 244, 6049-6055.

Miller, A. F. (2012). Superoxide dismutases: ancient enzymes and new insights. FEBS Lett. 586, 585-595. doi: 10.1016/j.febslet.2011.10.048

Mittler, R., and Blumwald, E. (2010). Genetic engineering for modern agriculture: challenges and perspectives. Annu. Rev. Plant Biol. 61, 443-462. doi: 10.1146/annurev-arplant-042809-112116

Mittler, R., Vanderauwera, S., Gollery, M., and Breusegem, F. V. (2004). Reactive oxygen gene network of plants. Trends Plant Sci. 9, 490-498. doi: 10.1016/j.tplants.2004.08.009

Molina-Rueda, J. J., Tsai, C. J., and Kirby, E. G. (2013). The Populus superoxide dismutase gene family and its responses to drought stress in transgenic poplar overexpressing a pine cytosolic glutamine synthetase (GS1a). PLoS ONE 8:e56421. doi: 10.1371/journal.pone.0056421

Moller, I. M. (2001). Plant mitochondria and oxidative stress: electron transport, NADPH turnover, and metabolism of reactive oxygen species. Annu. Rev. Plant Physiol. Biol. 52, 561-591. doi: 10.1146/annurev.arplant.52.1.561

Moran, J. F., James, E. K., Rubio, M. C., Sarath, G., Klucas, R. V., and Becana, M. (2003). Functional characterization and expression of a cytosolic iron-superoxide dismutase from cowpea root nodules. Plant Physiol. 133, 773-782. doi: 10.1104/pp.103.023010

Mueller, L. A., Solow, T. H., Taylor, N., Skwarecki, B., Buels, R., Binns, J., et al. (2005). The SOL genomics network: a comparative resource for Solanaceae biology and beyond. Plant Physiol. 138, 1310-1317. doi: 10.1104/pp.105.060707

Osakabe, Y., Yamaguchi-Shinozaki, K., Shinozaki, K., and Tran, L. S. P. (2014). ABA control of plant macroelement membrane transport systems in response to water deficit and high salinity. New Phytol. 202, 35-49. doi: 10.1111/nph.12613

Pan, L. J., and Jiang, L. (2014). Identification and expression of the WRKY transcription factors of Carica papaya in response to abiotic and biotic stresses. Mol. Biol. Rep. 41, 1215-1225. doi: 10.1007/s11033-013-2966-8

Perl, A., Perl-Treves, R., Galili, S., Aviv, D., Shalgi, E., Malkin, S., et al. (1993). Enhanced oxidative-stress defense in transgenic potato expressing tomato $\mathrm{Cu}, \mathrm{Zn}$ superoxide dismutases. Theor. Appl. Genet. 85, 568-576. doi: 10.1007/BF00220915

Perl-Treves, R., Abu-Abied, M., Magal, N., Galun, E., and Zamir, D. (1990). Genetic mapping of tomato cDNA clones encoding the chloroplastic and the cytosolic isozymes of superoxide dismutase. Biochem. Genet. 28, 543-552. doi: 10.1007/BF00554381

Perl-Treves, R., and Galun, E. (1991). The tomato Cu, $\mathrm{Zn}$ superoxide dismutase genes are developmentally regulated and respond to light and stress. Plant Mol. Biol. 17, 745-760. doi: 10.1007/BF00037058

Perl-Treves, R., Nacmias, B., Aviv, D., Zeelon, E. P., and Galun, E. (1988). Isolation of two cDNA clones from tomato containing two different superoxide dismutase sequences. Plant Mol. Biol. 11, 609-623. doi: 10.1007/BF00017461

Pilon, M., Ravet, K., and Tapken, W. (2011). The biogenesis and physiological function of chloroplast superoxide dismutases. Biochim. Biophys. Acta 1807, 989-998. doi: 10.1016/j.bbabio.2010.11.002

Postel, D., Vanlemmens, P., Gode, P., Ronco, G., and Villa, P. (2002). Plantcare, a database of plant cis-acting regulatory elements and a portal to tools for in silico analysis of promoter sequences. Nucleic Acids Res. 30, 325-327. doi: $10.1093 / \mathrm{nar} / 30.1 .325$

Puget, K., and Michelson, A. M. (1974). Isolation of a new copper-containing superoxide dismutase bacteriocuprein. Biochem. Biophys. Res. Commun. 58, 830-838. doi: 10.1016/S0006-291X(74)80492-4

Rabinowitch, H. D., and Sklan, D. (1980). Superoxide dismutase: a possible protective agent against sunscald in tomatoes (Lycopersicon esculentum Mill.). Planta 148, 162-167. doi: 10.1007/BF00386417

Sakuma, Y., Qiang, L., Dubouzet, J. G., Abe, H., Shinozaki, K., and YamaguchiShinozaki, K. (2002). DNA-Binding specificity of the ERF/AP2 domain of Arabidopsis, DREBs, transcription factors involved in dehydration- and coldinducible gene expression. Biochem. Biophys. Res. Commun. 290, 998-1009. doi: 10.1006/bbrc.2001.6299

Sasidharan, S., Kulangara, N. R., and Sailas, B. (2013). Biotic stress induced biochemical and isozyme variations in ginger and tomato by Ralstonia solanacearum. Am. J. Plant Sci. 4, 1601-1610. doi: 10.4236/ajps.2013.48194

Schützendübel, A., and Polle, A. (2002). Plant responses to abiotic stresses: heavy metal-induced oxidative stress and protection by mycorrhization. J. Exp. Bot. 53, 1351-1365. doi: 10.1093/jexbot/53.372.1351 
Shi, Z., Maximova, S. N., Liu, Y., Verica, J., and Guiltinan, M. J. (2010). Functional analysis of the Theobroma cacao NPR1 gene in Arabidopsis. BMC Plant Biol. 10:248. doi: 10.1186/1471-2229-10-248

Singh, V. K., and Jain, M. (2015). Genome-wide survey and comprehensive expression profiling of Aux/IAA gene family in chickpea and soybean. Front. Plant Sci. 6:918. doi: 10.3389/fpls.2015.00918

Soydam, A. S., Büyük, I., and Aras, S. (2013). Relationships among lipid peroxidation, SOD enzyme activity, and SOD gene expression profile in Lycopersicum esculentum L. exposed to cold stress. Genet. Mol. Res. 12, 32203229. doi: 10.4238/2013.August.29.6

Srivastava, V., Srivastava, M. K., Chibani, K., Nilsson, R., Rouhier, N., Melzer, M., et al. (2009). Alternative splicing studies of the reactive oxygen species gene network in Populus reveal two isoforms of high-isoelectric-point superoxide dismutase. Plant Physiol. 149, 1848-1859. doi: 10.1104/pp.108.133371

Sun, L. H., Shen, L. T., and Ye, S. (2007). Simultaneous overexpression of both $\mathrm{Cu} / \mathrm{Zn}$ superoxide dismutase and ascorbate peroxidase in transgenic tall fescue plants confers increased tolerance to a wide range of abiotic stresses. J. Plant Physiol. 164, 1626-1638. doi: 10.1016/j.jplph.2007.01.003

Tamura, K., Peterson, D., Peterson, N., Stecher, G., Nei, M., and Kumar, S. (2011). MEGA5 : molecular, evolutionary, genetics, analysis, using maximum, likelihood, evolutionary, distance, and maximum, parsimony, methods. Mol. Biol. Evol. 28, 2731-2739. doi: 10.1093/molbev/msr121

Tepperman, J. M., and Dunsmuir, P. (1990). Transformed plants with elevated levels of chloroplastic SOD are not more resistant to superoxide toxicity. Plant Mol. Biol. 14, 501-511. doi: 10.1007/BF00027496

Tuskan, G. A., Difazio, S., Jansson, S., Bohlmann, J., Grigoriev, I., Hellsten, U., et al. (2006). The genome of black cottonwood, populus trichocarpa (Torr.\&Gray). Science 313, 1596-1604. doi: 10.1126/science.1128691

Wang, B., Lüttge, U., and Ratajczak, R. (2004). Specific regulation of SOD isoforms by $\mathrm{NaCl}$ and osmotic stress in leaves of the C3, halophyte Suaeda salsa L. J. Plant Physiol. 161, 285-293. doi: 10.1078/0176-1617-01123

Wang, H. W., and Prabakaran, N. (2011). 2,4-dichlorophenoxyacetic acid-induced leaf senescence in mung bean (Vigna radiata L. Wilczek) and senescence inhibition by co-treatment with silver nanoparticles. Plant Physiol. Biochem. 49, 168-177. doi: 10.1016/j.plaphy.2010.11.007

Wei, K. F., Chen, J., Chen, Y. F., Wu, L. J., and Xie, D. X. (2012). Molecular phylogenetic and expression analysis of the complete WRKY transcription factor family in maize. DNA Res. 19, 153-164. doi: 10.1093/dnares/dsr048
Wispé, J. R., Warner, B. B., Clark, J. C., Dey, C. R., Neuman, J., Glasser, S. W., et al. (1992). Human Mn-superoxide dismutase in pulmonary epithelial cells of transgenic mice confers protection from oxygen injury. J. Biol. Chem. 267, 23937-23941.

Wu, G., Wilen, R. W., Robertson, A. J., and Gusta, L. V. (1999). Isolation, chromosomal localization, and differential expression of mitochondrial manganese superoxide dismutase and chloroplastic copper/zinc superoxide dismutase genes in wheat. Plant Physiol. 120, 513-520. doi: 10.1104/pp.120.2.513

Xia, Z., Liu, Q., Wu, J., and Ding, J. (2012). ZmRFP1, the putative ortholog of SDIR1, encodes a RING-H2 E3 ubiquitin ligase and responds to drought stress in an ABA-dependent manner in maize. Gene 495, 146-153. doi: 10.1016/j.gene.2011.12.028

Xu, G., Guo, C., Shan, H., and Kong, H. (2012). Divergence of duplicate genes in exon-intron structure. Proc. Natl. Acad. Sci. U.S.A. 109, 1187-1192. doi: 10.1073/pnas.1109047109

Yang, X., and Tuskan, G. A. (2008). The F-box gene family is expanded in herbaceous annual plants relative to woody perennial plants. Plant Physiol. 148, 1189-1200. doi: 10.1104/pp.108.121921

Youn, H. D., Kim, E. J., Roe, J. H., Hah, Y. C., and Kang, S. O. (1996). A novel nickel-containing superoxide dismutase from streptomyces spp. Biochem. J. 318, 889-896. doi: 10.1042/bj3180889

Zelko, I. N., Mariani, T. J., and Folz, R. J. (2002). Superoxide dismutase multigene family: a comparison of the CuZn-SOD (SOD1), Mn-SOD (SOD2), and ECSOD (SOD3) gene structures, evolution, and expression. Free Radic. Biol. Med. 33, 337-349. doi: 10.1016/S0891-5849(02)00905-X

Conflict of Interest Statement: The authors declare that the research was conducted in the absence of any commercial or financial relationships that could be construed as a potential conflict of interest.

Copyright (c) 2016 Feng, Yu, Cheng, Ruan, Wang, Ye, Zhou, Li, Yao, Yang, Zheng and Wan. This is an open-access article distributed under the terms of the Creative Commons Attribution License (CC BY). The use, distribution or reproduction in other forums is permitted, provided the original author(s) or licensor are credited and that the original publication in this journal is cited, in accordance with accepted academic practice. No use, distribution or reproduction is permitted which does not comply with these terms. 